\title{
Impact of TEAMS Clubs: An Afterschool Engineering Enrichment Program that Impacts K-12 Students and College Student Leaders
}

\author{
Ms. Janet L. Yowell, University of Colorado Boulder
}

Janet serves as the Associate Director of K-12 Engineering Education for the College of Engineering and Applied Science at the University of Colorado Boulder. Involved since 2000, she collaborates on the College's ambitious K-12 engineering initiatives, including their capacity-building and school partnership programs. She coordinates the Integrated Teaching and Learning Program's NSF-funded TEAMS Program (Tomorrow's Engineers... creAte. iMagine. Succeed.) which engages more than 2,200 K-12 students in engineering throughout the academic year and summer months. She is also a contributing curriculum writer and editor for the TeachEngineering digital library, also an NSF-funded project. Janet holds a B.A. in Communication from CU-Boulder and is currently pursuing a master's degree in Information and Learning Technology at CU-Denver.

\section{Dr. Malinda S Zarske, University of Colorado, Boulder}

Dr. Malinda S. Zarske is the director of K-12 Engineering Education at the University of Colorado Boulder's College of Engineering and Applied Science. A former high school and middle school science and math teacher, she has advanced degrees in teaching secondary science from the Johns Hopkins University and in civil engineering from CU-Boulder. She is also a first-year Engineering Projects instructor, faculty advisor for SWE, and on the development team for the TeachEngineering digital library. Her primary research interests are on student identity, recruitment, and retention in K-12 and undergraduate engineering.

\section{Dr. Daniel Knight, University of Colorado, Boulder}

Daniel W. Knight is the engineering assessment specialist at the Integrated Teaching and Learning Program (ITLL) and the Broadening Opportunity through Leadership and Diversity (BOLD) Center in CU's College of Engineering and Applied Science. He holds a B.A. in Psychology from the Louisiana State University, and an M.S. in Industrial/Organizational Psychology and a Ph.D. degree in Counseling Psychology both from the University of Tennessee. Dr. Knight's research interests are in the areas of retention, program evaluation and teamwork practices in engineering education. His current duties include assessment, evaluation and research for the ITL Program's and BOLD Center's hands-on initiatives.

\section{Dr. Jacquelyn F. Sullivan, University of Colorado, Boulder}

Jacquelyn F. Sullivan is founding co-director of the Integrated Teaching and Learning Program, and associate dean for inclusive excellence at the University of Colorado Boulder's College of Engineering and Applied Science. She received her Ph.D. in environmental health physics and toxicology from Purdue University and held leadership positions in the energy and software industries for thirteen years. She founded and leads CU's extensive K-12 engineering initiative and the BOLD Center, and spearheaded the Engineering GoldShirt Program. She led the founding of the ASEE K-12 Division in 2004, was awarded ASEE's 2005 Lifetime Achievement Award, and was conferred as an ASEE fellow member in 2011. She was awarded NAE's 2008 Gordon Prize for Innovation in Engineering and Technology Education. 


\title{
Impact of TEAMS Clubs: An Afterschool Engineering Enrichment Program that Impacts K-12 Students and College Student Leaders
}

\begin{abstract}
Many examples of university engineering education programs designed to impact K-12 student learning and access are described in the literature. Unfortunately, most do not report repeated engagement with students who are assessed over time. There is a need to better determine the results of evolving engineering instruction in K-12 schools and the best practices for implementation.
\end{abstract}

This paper discusses a successful model for a weekly afterschool elementary engineering enrichment program that has been in place for six years. TEAMS clubs, named after an umbrella K-12 engineering education initiative (Tomorrows Engineers... creAte. iMagine. Succeed.) at the University of Colorado Boulder, are led by undergraduate engineering students, using handson activities that allow students to learn first-hand that engineering is creative and explorative. The school-based TEAMS Clubs are popular, oftentimes with more students interested in participating than there is space. Many of the elementary students in TEAMS Clubs are concurrently engaged in engineering learning opportunities during an in-class, academic-year NSF-funded GK-12 program. To supplement the in-class program goals, the afterschool TEAMS Clubs also expand the knowledge of and exposure to engineering careers.

While program assessment has been at the core of these clubs since their inception, the impacts of the TEAMS Clubs have not been previously reported in the literature. To understand student perceptions of their repeated and frequent exposure to engineering, pre/post engineering attitudes are assessed for students in grades 3-5 in nine partner elementary schools. TEAMS Club leader impact is also discussed, supporting the theory that the clubs have a broader effect than on the elementary students themselves. Hosting teachers are also surveyed to glean their feedback on the clubs' value. Additionally, information is provided on how schools elsewhere can replicate and implement the TEAMS model, with minimal funding and high impact. The TeachEngineering digital library, also an NSF-funded initiative, is revealed as a primary source for TEAMS Clubs curricular activities.

\section{Need for Research}

In discussing the engineering profession with high school-aged students, the questions still arise, “Can I be an engineer?” and “Should I be an engineer?” Despite our profession's attempts to educate citizens on engineering as a viable career option, well-prepared high school students often do not consider an engineering future, and doubt their ability to perform in an engineering capacity. At some point, a parent, another influential adult or a counselor may have informed them that only students who love math and science and are willing to endure the intensity and rigors of a formal engineering education can become engineers.

As stated by Turner and Lapan, youth begin the formation of their career identities as early as $3^{\text {rd }}$ grade, according to their understanding of gender-appropriateness of certain occupations. ${ }^{1,2}$ 
Therefore, the need exists to create a solid foundation for understanding the benefits and rewards of an engineering career before students, particularly young girls, become misinformed by public perceptions. Recent research found that K-12 students and teachers have a poor perception of what engineers do. ${ }^{3}$ Whose responsibility is it to properly inform the public?

Despite continuous improvement between 1990-2006 in math and science performance, U.S. students still fall short in these subjects as compared to their peers in other nations. ${ }^{4}$ In some $\mathrm{K}-12$ schools, students might consider their failure in math and science as a means to being accepted-in other words, failure is perceived to be the social norm. ${ }^{5}$ Well thought-out, engaging engineering activities, presented as extension opportunities for K-12 students, could do double time: help students who are interested in engineering stay on track and interest other students early on about the possibilities of an engineering future. $\mathrm{K}-12$ engineering education is linked with the improvement of student learning and achievement in mathematics and science. ${ }^{6}$ Imagine the outcomes if our nation's schools pervasively integrated effective engineering education into their curriculum on a regular basis; the impact could have a staggering effect on our nation's future workforce.

Engineering education programs engaging elementary-aged students are timely and well poised to both inform and help correct societal misperceptions of engineering among youth. While it is important that we communicate that students must not love math to be an engineer, it is also important that we prepare them so that they can do math competently. In other words, we must do a better job of identifying and nurturing our nation's math-capable youth. ${ }^{7}$

Afterschool programs are a practicable venue for capturing and nurturing students' attention and energies through a structured environment in which they both grow academically and form relationships with adult STEM role models. ${ }^{8,9}$ Students' participation in extracurricular learning after school speaks to their interest-or at least a willingness—-to further their own knowledge. Children are sponges for new knowledge; how better to saturate their sponge than through handson, engaging activities that make them want to learn —and about engineering specifically?

\section{Literature Review}

\section{Value of Extracurricular Learning on K-12 Students}

With regard to the influence afterschool programs have on school-aged children, the research is varied. Debate exists in the design of pre-college education programs on which comes first: nurturing an early interest in engineering and critical thinking skills or focusing on the preparation of those already interested in collegiate pursuit of engineering. ${ }^{5}$ Schunn asserts that we cannot have one without the other; that to have prepared students, they must be exposed to engineering to create a funnel of interested students. He further espouses that while college-aged curriculum is not appropriate for younger children, school-aged children are capable of engaging in "relatively sophisticated" engineering design activities under the right learning conditions. ${ }^{5}$

Fantz et al. found that of 332 first-year students enrolled in a college of engineering, "a student exposed to pre-college engineering content will be more likely to pursue and succeed in engineering." ${ }^{10}$ Informal or formal methods of engineering exposure, they reported, are both 
effective means for engaging K-12 students in the field at an early age. Their research further explored the differences in self-efficacy among engineering students who had pre-college engineering experiences vs. those who did not. They found that although much literature exists on the factors that affect self-efficacy of students in college, little research is available on the value of pre-college experiences in affecting a student's judgment of their own capabilities.

\section{Value of Extracurricular Volunteer Service on University Students}

Ample research supports the benefits of service learning on students' collegiate experience, both when embedded as a curricular requirement and as an extracurricular offering. Our literature search looked into both types of experiences: that in which outreach is offered outside of regular, required coursework and that which is completed through—or because of—course requirements.

Seminal research by Astin and Sax of more than 2,300 first-year college students at 42 institutions found that students volunteer to, quite simply, help others and to feel a level of personal satisfaction. ${ }^{11}$ In surveying twenty-three engineering students at Tufts University who participate in K-12 engineering outreach programs, Pickering et al. also found a similar result: university students express feelings of accomplishment when K-12 students apply the same engineering principles that the college students are learning in their own projects. ${ }^{12}$ Their research further found that while both were positively impacted, university outreach programs had a stronger impact on females than on males.

Astin and Sax report that the number one finding of why college students volunteer is that the experience "enhanced the student's academic development, civic responsibility, and life skills."11 This speaks to the argument that students who teach others about their passions (in this case, engineering) are more likely to absorb and personalize the subject matter than if they do not translate that information to other audiences. With regard to the idea of academic development, Astin and Sax also found that education-related service (that is, teaching/tutoring) enhances the student's college GPA and furthers their general knowledge of a field or discipline, along with increasing their time devoted to their academics (that is, homework and studying). They also report that a student's aspirations for advanced degrees are also positively affected by engaging in service-related academic endeavors.

Perhaps the community service aspect is the most important factor in the undergraduate student experience. To capitalize on recent research on service-learning experiences, Edginton Bigelow assigned a service-learning course component to undergraduate engineering students to evaluate how best to inform the public about engineering, particularly the biomechanical field. ${ }^{13}$ The service-learning component was assigned to fifteen students enrolled in a biomechanical engineering course to engage pre-college students in designing a hands-on prosthetic activity. The assignment yielded a surprise outcome: not only were college students amazed at the overall intelligence and creativity of girls and boys under the age of 18, they were surprised to learn of their own ability (or inability) to teach to young audiences. They realized how difficult it is to communicate technical material to non-technical audiences. The college students also reported their own positive interest in being role-models, mentors and coaches for younger students. 
From a gender perspective, Pickering et al. found that "working with students and conveying the importance of engineering to society provides female engineers with the real-world connection that many have reported helps retain women in technical fields. In addition, their data suggest a higher confidence level regarding engineering content, another factor linked to retaining women in engineering." $" 12$ This supports the idea that female students are more positively impacted by education-related service activities than male students.

With regard to the value of engineering education on K-12 students, there is agreement among researchers that early exposure to engineering does increase the pipeline of students who enter the engineering field as well contribute in some fashion to the self-efficacy of those who pursue engineering later on as a career.

\section{Research Goals}

We find that, supporting the advice of Schunn, modeling the engineering design cycle for children is an essential component for their true understanding of the concepts of engineering. ${ }^{5}$ All TEAMS Club activities follow a pattern for design-based student engagement: identify the problem, brainstorm ideas, design solutions, build a prototype device, test the device, reflect, redesign/improve the device. The value of engineering design being practiced by the volunteers and modeled for the elementary students leaves a lasting impression on both groups in terms of engineering interest and problem-solving development. ${ }^{14,15}$

This research aimed to discover the impact of the University of Colorado Boulder's afterschool K-12 engineering education initiative through exploring the following question: do afterschool engineering experiences positively impact elementary students and undergraduate student leaders?

\section{Background}

The goal of the afterschool TEAMS Clubs is to expose elementary-aged girls and boys frequently in engineering in an extracurricular setting in their own learning environment. During the past six years, nearly 700 grades 3-5 students have experienced engineering through the University of Colorado Boulder's (CU-Boulder) afterschool TEAMS Club initiative. For 12 weeks each fall and spring semester, CU-Boulder engineering students volunteer their time to "give back" to their community; they commit to commit one afternoon each week for the entire semester. An average of 25 undergraduate engineering students engage each semester, volunteering their time for students who are traditionally underrepresented in the field of engineering-low-income youth, children of color and girls.

The TEAMS Clubs serve as added enrichment for students at six of the nine schools, in that those schools are also associated with CU-Boulder's NSF-funded GK-12 Program, wherein $5^{\text {th }}$ grade students also engage in concurrent 1-2x per/semester multi-week engineering projects provided through an in-class engineering education program that is instructed by $\mathrm{PhD}$ engineering students. However, we suspected that even though six of the schools have the additional GK-12 influence, the three schools that do not would have similar gains in their attitudes about and interest in engineering. 
Nearly 150 unique CU-Boulder engineering college students have participated in leading TEAMS Clubs since 2006, the majority ${ }^{\mathrm{a}}$ of which led the clubs through volunteerism. Many of the leaders are active in the college's Engineering Honor's Program and report (anecdotally) that they have contributed to "giving back" to their community since their early teen years. Thus, the idea of volunteering is second nature for them, and they give their time willingly. Their enthusiasm for volunteerism has enticed their non-Honors Program engineering peers to participate as well.

Another subset of the volunteers are engineering merit scholarship recipients or members of engineering student societies, who participate because they have a service learning/community participation requirement for renewing their scholarship or because they too want to give back.

\section{Methods}

Week after week, elementary students explore basic principles of engineering through fun, hands-on projects that spark their imaginations and engage their minds. The young students work in teams to create engineering projects that integrate age and development-appropriate science and mathematics. These "design, build, test, and evaluate" experiences help them gain an understanding of the pervasiveness of engineering in their world as well as an awareness of how engineering benefits humanity and our planet.

And, diversifying the engineering workforce is a priority for the TEAMS initiative; the weekly TEAMS clubs empower elementary students from all backgrounds to envision themselves as future engineers, scientists and mathematicians.

\section{TEAMS Club Structure}

Each fall and spring semester, CU-Boulder undergraduate students commit to lead the TEAMS Clubs. Each of the volunteers - recruited via signs and flyers, email and word of mouth-is assigned to one school for the entire semester, based on their course schedule and car availability (necessary for our setting). Engineering students who have led clubs in the past have priority, as they are effective role models for new leaders, as well as the K-12 students.

Six of the nine elementary schools are part of the same high school feeder system (including two middle schools and one high school) — an audience with whom CU-Boulder engages with through their GK-12 grant. And, three of the other elementary schools were partners through a previous GK-12 initiative. Schools determine which day of the week (Monday through Thursday) works best for the afterschool offering.

Each of the clubs is 55-75 minutes in duration and is assigned 2-4 undergraduate leaders. The TEAMS Clubs attract 15-25 students each. Because of a club size limitation (physical space and a desired mentor-to-student ratio of $\sim 5$ students per college student leader), teachers leave many

\footnotetext{
${ }^{\text {a }}$ During the 2006-2007 academic year, six undergraduate leaders were paid an hourly wage to lead four afterschool clubs. After the initial success and popularity of the clubs, and for reasons of sustainability, the practice of paying students to teach TEAMS Clubs was discontinued.
} 
students on a waitlist each semester. Framed by teachers as just a momentary setback, this participation delay for waitlisted students has not hindered the clubs' reputation- they remain wildly popular at each school for young students. The schools are responsible for soliciting student participants, with the requirement that they must attempt to enroll 50\% female and 50\% underrepresented minority students, backfilling with other students if demand warrants. For reference, Table 1 shows each school's demographics by percent students receiving free/reduced lunch and percent students who are minority. Some schools offer personal invitations to targeted students; others open up registration school-wide and employ a lottery drawing if there is more demand than the clubs can accommodate.

Table 1. TEAMS Club School Demographics

\begin{tabular}{|l|l|}
\hline School Name & \multicolumn{1}{|c|}{ Demographics } \\
\hline Alpine Elementary School & 29\% free/reduced lunch; 32\% minority \\
\hline Columbine Elementary School & $91 \%$ free/reduced lunch; 87\% minority \\
\hline Fall River Elementary School & 15\% free/reduced lunch; 24\% minority \\
\hline Lafayette Elementary School & 24\% free/reduced lunch; 19\% minority \\
\hline Loma Linda Elementary School & 81\% free/reduced lunch; 81\% minority \\
\hline Rocky Mountain Elementary School & $91 \%$ free/reduced lunch; 93\% minority \\
\hline Ryan Elementary School & 26\% free/reduced lunch; 24\% minority; \\
\hline Sanchez Elementary School & 74\% free/reduced lunch; 68\% minority \\
\hline Spangler Elementary School & $96 \%$ free/reduced lunch; 89\% minority \\
\hline
\end{tabular}

Although each of the schools are "partner" schools, their after-school participation is voluntary. They provide some investment in that the school arranges for the hosting teacher's time, as well as provides instructional space. CU-Boulder provides all activity supplies (supported in part through private donations), along with the engineering club leaders. Many of the teachers who host the clubs have participated for years; they receive no financial support from the university.

To promote engagement, no fee is charged for the clubs. CU-Boulder supplies a registration form-an application form that features the messaging recommendations in NAE's Changing the Conversation Study ${ }^{3}$, in terms of language and imagery to attract young people to engineeringfor use by schools to solicit participation.

\section{Weekly Activity Execution and Selection}

To learn the early value of teamwork, elementary students in each club are broken up into groups of 3-4. A different hands-on engineering activity is prepared for the club each week, selected with teamwork and the engineering design process in mind. Age appropriate, inexpensive activities are selected in the first few weeks of the semester for use the entire 12-week period; with 12 unique activities rotated through the nine different clubs. A master schedule is developed, a supplies list is created, and all supplies are purchased. The supplies are assembled into weekly activity kits, refilled after each use.

The weekly activity kit is put together in a plastic bin, with enough supplies for the number of groups per school, along with an activity instruction sheet and any accompanying worksheets. 
Each activity is presented for leaders with easy-to-follow instructions and includes background information, thought-provoking questions to help get students thinking like engineers, as well as closing/reflection comments that provide activity closure. The activity preparation is repeated every week by a part-time student working about three hours weekly to keep the kits filled and labeled. The kits are generally assembled on Friday afternoons for the next week.

The low-cost, fun activities are usually chosen from TeachEngineering digital library (http://www.teachengineering.org), an online warehouse of $>1200$ hands-on engineering lessons and activities - a project that was initiated by the University of Colorado Boulder and funded by NSF. The advanced search option in TeachEngineering allows for the differential selection of activities that are geared toward either specific subjects, time duration, supplies that are available/leftover, and age, among other criteria. The activities are also selected such that TEAMS Club leaders can readily present different topics each week without being required to do homework before they lead a club. By using activities from TeachEngineering, there is educational standard alignment for all of the activities that are taught in the clubs —an added bonus for the schools.

\section{Data Collection}

Data collection employed a mixed-method approach, with quantitative and qualitative assessment data collected to assess: 1) K-12 program participants' attitudes about engineering, 2) CU-Boulder club leaders' experiences leading an afterschool engineering TEAMS Club, and 3) the hosting teachers' perceived value of the clubs. For each group, quantitative methods included a survey with five-point Likert-type style questions; qualitative methods included openended survey questions. The data were entered into Microsoft Excel ${ }^{\circledR}$ and quantitative data were analyzed using the Statistical Package for the Social Sciences ${ }^{\circledR}$ (SPSS).

\section{Research Setting and Participants}

The research took place during the fall semester across three years: 2009, 2011 and 2012 at the University of Colorado Boulder's College of Engineering and Applied Science. Research participants included 264 grades 3-5 students who were surveyed at both the beginning and end of their TEAMS Club experience. Respondents were 31\% female. The survey was in the form of a paper survey administered by the club leader prior to the first and last activity (approximately 12 weeks later).

The TEAMS Club leaders, both current $(n=24)$ and former $(n=100)$, were surveyed via an online survey (link sent via email) for feedback on their experiences leading a club at the end of the fall 2012 semester. Data was received from 20 current and 14 former leaders who led clubs at nine schools. Former leaders were $79 \%$ female while current leaders were $60 \%$ female. All TEAMS Club leaders are/were undergraduate engineering students enrolled at the University of Colorado Boulder's College of Engineering and Applied Science.

Current hosting teachers $(n=9)$ were also surveyed to obtain their feedback on their perceived value of the TEAMS Clubs for students. Data was received from six teachers. 


\section{Surveys}

The elementary student survey was comprised of ten questions, six devoted to knowledge of engineering as a career and four dedicated to interest in engineering. The survey questions were modified from the College's existing first-year engineering projects course survey, and the language was scaled for a younger audience. Two additional qualitative questions were asked at the end of the survey, of which the analysis was not included as part of this paper. The same survey was administered for each pre/post and during all of the semesters (see Appendix for a copy of the survey questions). The pre/post survey was also offered in Spanish to avoid any confusion with terms presented in English.

Both former and current TEAMS Clubs leaders and current partner teachers completed a survey to assess their perceptions of the impacts of the program. The leader survey focused on the development of their technical and professional engineering skills, and the impact of being a leader on future academic and career choices. The quantitative questions were five-point Likerttype style questions; the qualitative questions asked open-ended survey questions (see Appendix for a copy of the survey).

Surveys for all participating students were conducted under the University's Institutional Review Board (IRB) approval. Student responses were coded to protect participant identity.

\section{Findings}

Elementary student responses ( $\mathrm{n}=264,38 \%$ of total participants over three years/six semesters) to the attitude survey were analyzed using a repeated measures ANOVA procedure to test for differences pre/post and between genders. Results revealed a significant gain $(\mathrm{p}<.05)$ between the pre- $($ mean $=4.50)$ and post-assessment (mean $=4.63$ ) for interest in engineering and a significant gain pre (mean $=3.73$ ) to post (mean $=4.35$ ) for knowledge of engineering as a career (see Figure 1). These results are further supported by frequent (anecdotal) student comments, as reported by the club leaders, such as "This is fun. I want to be an engineer." Or "I never knew that I could do engineering." Results did not reveal differences between genders, age or grade.

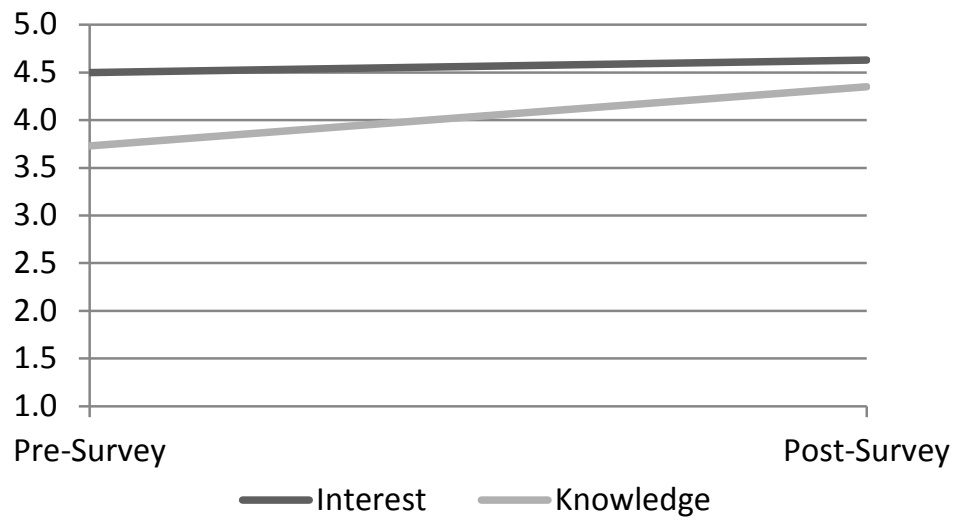

Figure 1. Elementary student pre/post gains in interest in and knowledge of engineering. 
As suspected, all schools-even the three schools who are not concurrently engaged in the inclass engineering program offered by CU-Boulder-revealed an increase in interest and knowledge in engineering, demonstrating that the afterschool program alone has a positive effect on the perceptions of the students who participate. Table 2 delineates the pre-/post-variance in each of the ten survey questions (see Appendix for text of the survey questions).

Table 2. Pre/Post Variance of Individual Survey Questions.

\begin{tabular}{|l|c|c|c|}
\hline \multicolumn{1}{|c|}{ Subscale } & Question & Pre-Assessment & Post-Assessment \\
\hline Knowledge & 1 & 3.95 & 4.63 \\
\hline Knowledge & 2 & 4.36 & 4.61 \\
\hline Knowledge & 4 & 4.33 & 4.60 \\
\hline Knowledge & 5 & 4.42 & 4.56 \\
\hline Knowledge & 8 & 4.37 & 4.62 \\
\hline Knowledge & 9 & 3.93 & 4.25 \\
\hline Interest & 3 & 4.44 & 4.45 \\
\hline Interest & 6 & 3.34 & 3.60 \\
\hline Interest & 7 & 4.24 & 4.27 \\
\hline Interest & 10 & 4.56 & 4.40 \\
\hline
\end{tabular}

Table 3 indicates the impact of the TEAMS Club leader experience on their own engineering skills, satisfaction and future academic and career choices. Numbers in the table represent a combined percentage of leaders who either agreed or strongly agreed to each of the impact items.

Table 3. Percent Agreement on Impact of Serving as a TEAMS Club Leader.

\begin{tabular}{|l|c|c|}
\hline Impact Items & $\begin{array}{c}\text { Former TEAMS } \\
\text { Leaders }\end{array}$ & $\begin{array}{c}\text { Current TEAMS } \\
\text { Leaders }\end{array}$ \\
\hline Oral Communication Skills & $85 \%$ & $85 \%$ \\
\hline Fundamental Engineering Skills & $39 \%$ & $55 \%$ \\
\hline Future Career Plans & $39 \%$ & $35 \%$ \\
\hline Satisfaction w/Engineering Studies & $85 \%$ & $75 \%$ \\
\hline Undergraduate Course Selections & $15 \%$ & $0 \%$ \\
\hline
\end{tabular}

Analysis indicated that the main impacts of leading TEAMS clubs were in the development of oral communication skills and fostering satisfaction with engineering studies. One leader commented on oral communication skills development: "I was previously not a very good public speaker, but after having to go up and teach tough concepts to children in front of a blackboard, my skills greatly improved. I was forced to learn to speak more slowly, and clearly, and it made me think before I was to speak about a concept. Since the concepts were sometimes difficult to grasp, I had to be able to speak about them with simplicity.”

Regarding satisfaction with engineering studies, one leader commented, "Engineering is tough and going to the TEAMS Clubs every week helped alleviate a lot of the stress and therefore made my classes more enjoyable.” Another student responded that the greatest benefit they got 
out of leading a TEAMS Club was, "The chance to interact with excited and enthusiastic kids. Seeing them was the best part of my week!”

TEAMS Club leadership had less of an impact on undergraduate course selection and future career plans. Leaders felt that their majors and course selections were already chosen prior to joining TEAMS, but that the experience solidified those choices. One leader stated, "I was already decided about my major before joining TEAMS.” Former and current leaders were similar in their responses. However, current leaders were more aware of the impact on their development of fundamental engineering skills, while former leaders were more satisfied with the enduring impact on their engineering knowledge and career choices.

Leaders were also assessed for impact of their club leader role on their own motivation. Both former and current leaders were asked if they signed up as a requirement (that is, to fulfill a scholarship or program service requirement) or volunteered for the role. Of former leaders, 86\% volunteered while $45 \%$ of current leaders volunteered. Former leaders were asked if they sought a job after graduation with K-12 outreach opportunities; $50 \%$ indicated yes. One former leader commented, "It was very important to me to find a company that had the same values as the TEAMS program.” Current leaders were queried as to whether they would like to continue as a TEAMS Club leader; 90\% indicated yes.

Much to our delight, $100 \%$ of teachers $(n=6)$ involved believe the TEAMS Club leaders at their school encouraged elementary students to consider engineering as a career choice. One hosting teacher stated: "We are very lucky and appreciative of the time and effort of the instructors. They make this program fun and interesting for the students. Thank you so much for what they do and how they do it." Another teacher offered the following feedback: "It isn't just an extracurricular program. It is a reward for hardworking students, who are allowed to learn more than can be covered in the regular day. The students look forward to what they learn and their instructors. It's a great program.” In fact, teachers responded unanimously (100\%) that they wish to have a TEAMS Club return to their school next semester-definitely a motivator to labor over activities and club schedules.

\section{Implications for Practice}

TEAMS Clubs appear to be an effective way to increase interest in engineering and knowledge of engineering as a career among elementary students, even when interest is already high. The lack of difference between genders in interest highlights the importance of targeting a young population before girls develop a bias against technical subjects.

TEAMS Club leadership appears to strengthen oral communication skills, which are valuable skills for our students when seeking employment and throughout their careers. Furthermore, it increases their level of satisfaction when they are in college, by offering a service-based experience different than their technical subjects. Many leaders are motivated to continue seeking an outreach component in their careers.

This program can be easily replicated, in that labor costs are almost nonexistent. The program uses a small materials budget, mileage reimbursement of volunteers, and a modest staffing 
budget for 6-8 hours a week of personnel time (for clubs organization and activity preparation). For most of the program's history, personnel time included a CU-Boulder program staff person and an undergraduate student coordinator ${ }^{\mathrm{b}}$ When possible, materials are reused.

Although some programs report a difficulty "getting in" with a school, our experience is that schools are ripe for extracurricular enrichment if the context is appropriate and little planning is required on the school's part. It has taken time to foster a working relationship with the teachers, but the rewards are plenty. Although time must be devoted to maintaining the program's weekto-week logistics, the college student leaders are reliable and enthusiastic.

One of the biggest issues to deal with is that of transportation; public transportation is not convenient in our suburban setting. Also, the leaders must carry the activity kits (bins stuffed to the brim with supplies) back and forth. We recognize that this universal issue varies by location.

The choice of activities is a challenge, given the mixed age of the club participants. The majority of elementary students who participate in the clubs cycle within a two-year period, so to keep them engaged, we avoid having them do the same activity twice; thus, we lead different activities for each of the fall and spring semesters and strive not to repeat any activity in a two-year timeframe. This does require good record keeping on activity selection.

\section{Limitations of Study and Suggestions for Future Research}

With regard to program participation, it is difficult to conduct longitudinal assessment due to the strict school district policy on releasing information on student identity. It is unknown, therefore, which students return year-after-year. Anecdotal feedback from teachers suggests that students who participate in the program are more likely to return in subsequent years. Many of the partner TEAMS Club schools support "transient" populations, as reported by teachers, with high levels of yearly student attrition. Also, many young students have inconsistent participation due to family commitments (oftentimes babysitting younger siblings).

The survey instrument was created to fulfill assessment requirements for CU-Boulder's NSFfunded GK-12 grant. Additional survey development is underway, and further validation is a planned future research action.

This research demonstrates that frequent, regular exposure to engineering increases elementary student interest in engineering and knowledge about engineering as a career. Further research on the longitudinal impacts would provide statistical relevance to the long-term impact of afterschool exposure and provide the answer to whether or not students enter the field of engineering because of their participation in the afterschool clubs.

The research on the impact to the undergraduate student leaders is valuable in reaffirming the importance of service learning in leading to personal fulfillment and increasing essential $21^{\text {st }}$ century skills.

\footnotetext{
${ }^{\mathrm{b}}$ The TEAMS Club program utilized the same undergraduate student coordinator for five years (the duration of her time at the university), who selected all activities, organized and prepared kits, for a $\$ 500 /$ semester stipend.
} 


\section{Conclusion}

One of this paper's primary goals was to discover the impact of afterschool engineering enrichment on elementary students, and we discovered that there is indeed an increase in interest in and knowledge of engineering as a career. These results echo previous research on engaging students pre-college, and support the need for bringing hands-on engineering experiences down to the earliest grades to increase engineering interest and awareness. In essence, engineering education efforts ultimately increase the pipeline, both in numbers and academic preparedness, of students who enter the engineering field.

Once the semester is underway - that is, leaders have been hired, activities have been selected and supplies have been gathered - the time investment in the clubs is minimal compared to the positive benefits to the youth who participate. And, we were pleased with the feedback from surveying our current and former TEAMS Clubs leaders and teachers, as this was uninvestigated territory. The impact the clubs have on the CU-Boulder student leaders has been unmistakably positive. One former student leader commented the following about her experience leading a TEAMS Club, "It definitely brings about a sense of community. Even after I graduated, I have met people that have participated in the TEAMS Clubs at my job and it immediately creates a bond between two people. And, being connected with the University and the TEAMS program is such a privilege for all the schools in City.” The teachers unanimously felt TEAMS Clubs have value and wish to work with them at their schools again next year.

The overall positive gain to college students is an investment that CU-Boulder is willing to undertake. Future research will be conducted on the long-term impact of the college student volunteers in understanding the impact on their retention in engineering studies.

\section{References}

[1] Turner, S. L., \& Lapan, R. T. (2005). Evaluation of an intervention to increase non-traditional career interests and career-related self-efficacy among middle-school adolescents. Journal of Vocational Behavior, 66, 516-531.

[2] Yowell, J. L., \& Sullivan, J. F. (2011). Who should be an engineer? Messaging as a tool for student recruitment and retention. The Bridge, Linking Engineering and Society, 41(2), 23-29. Washington, DC: National Academies Press.

[ 3] National Academy of Engineering (2008). Changing the conversation: Messages for improving public understanding of engineering. Washington, DC: National Academies Press.

[4] National Science Board (2012). Science and Engineering Indicators 2012. Arlington VA: National Science Foundation (NSB 12-01).

[5] Schunn, C. D. (2009). How kids learn engineering the cognitive science perspective. The Bridge, Linking Engineering and Society, Fall 2009, 32-37. Washington, DC: National Academies Press. 
[6] Katehi, L., Pearson, G., \& Feder, M. (2009). The status and nature of K-12 engineering education in the United States. The Bridge, Linking Engineering and Society, 39(3), 5-10. Washington, DC: National Academies Press,

[7] Hyde, J. S., \& Mertz, J. E. (2009). Gender, culture, and mathematics performance. Proceedings of the National Academy of Sciences, 26(22). Washington, DC: National Academies Press.

[8] Eccles, J. S., Barber, B. L., Stone, M., \& Hunt, J. (2003). Extracurricular activities and adolescent development. Journal of Social Issues, 59(4), 865-889.

[9] Gottfredson, D. C., Cross, A., \& Soulé, D. A. (2007). Distinguishing characteristics of effective and ineffective afterschool programs to prevent delinquency and victimization. Maryland Department of Human Resources and the Maryland Office of Children, Youth and Families (\#CCA/AFTER/02-008 A-1), 6(2), 2007, 289318.

[10] Fantz, T. D., Sillera, T. J., \& Demiranda, M. A. (2011). Pre-collegiate factors influencing the self-efficacy of engineering students. Journal of Engineering Education, 100(3), 604-623.

[11] Astin, A.W., \& Sax, L.J. (1998). How undergraduates are affected by service participation. Journal of College Student Development, 39(3), May/June 1998, 251-263.

[12] Pickering, M., Ryan, E., Conroy, K., Gravel, B., \& Portsmore, M. (2004). The benefit of outreach to engineering students. Proceedings, American Society for Engineering Education Annual Conference \& Exposition, June.

[13] Edginton Bigelow, K. (2010). Reflections of college students promoting engineering through biomechanical outreach activities indicate dual benefits. Proceedings, American Society for Engineering Education Annual Conference \& Exposition, June.

[14] Petroski H. (1996). Invention by design: How engineers get from thought to thing. Cambridge, MA: Harvard University Press.

[15] Cunningham, C. M., Hester, K. (2007). Engineering is elementary: An engineering and technology curriculum for children. Proceedings, American Society for Engineering Education Annual Conference \& Exposition, June. 


\section{Appendix}

TEAMS Club Participant Survey

\section{Afterschool TEAMS Club Engineering Post-Survey \\ Fall 2012}

This survey asks you some questions about engineering. Please circle your best answer for each question. Please remember to write your name at the top of this survey!

1. I know what an engineer does.
a. Definitely
b. Sort-of
c. Maybe
d. Not so much
e. Not at all

2. I think engineers help other people.
a. Definitely
b. Sort-of
c. Maybe
d. Not so much
e. Not at all

3. I want to learn more about how engineering makes the world better.
a. Definitely
b. Sort-of
c. Maybe
d. Not so much
e. Not at all

4. I believe that engineers create things I use every day.
a. Definitely
b. Sort-of
c. Maybe
d. Not so much
e. Not at all

5. I think engineers work a lot with other people.
a. Definitely
b. Sort-of
c. Maybe
d. Not so much
e. Not at all 
6. I can imagine myself becoming an engineer.
a. Definitely
b. Sort-of
c. Maybe
d. Not so much
e. Not at all

7. I want to explore how engineers shape the world we live in.
a. Definitely
b. Sort-of
c. Maybe
d. Not so much
e. Not at all

8. I believe engineers use their imagination to improve people's lives.
a. Definitely
b. Sort-of
c. Maybe
d. Not so much
e. Not at all

9. I have a sense for the kinds of things engineers do in their jobs.
a. Definitely
b. Sort-of
c. Maybe
d. Not so much
e. Not at all

10. I am interested in learning more about engineering.
a. Definitely
b. Sort-of
c. Maybe
d. Not so much
e. Not at all 


\section{TEAMS Club Leader Feedback Survey \\ Fall 2012}

Please circle your answer to the following questions on the scale provided below; explain your choice.

\section{$\mathrm{SD}=$ =strongly disagree; $\mathrm{D}=$ =disagree; $\mathrm{N}=$ neutral; $\mathrm{A}=$ =agree; $\mathrm{SA}=$ strongly agree}

1. Leading a TEAMS Club has helped strengthen your oral communication skills. $\quad$ SD $\quad$ D $\quad \mathrm{N} \quad A \quad S A$ Please explain:

2. Leading a TEAMS Club has helped strengthen your written communication skills. $\quad$ SD $\quad$ D $\quad N \quad A \quad S A$ Please explain:

3. Leading a TEAMS Club has helped strengthen your fundamental engineering $\quad$ SD $\quad$ D $\quad$ N $\quad$ A $\quad$ SA skills (i.e., calculus, physics, etc.)?

Please list and explain:

4. Your TEAMS experience has impacted your future career plans (after SD $\quad \mathrm{D} \quad \mathrm{N}$ A $\mathrm{SA}$ graduation).

Please explain:

5. Being a TEAMS Club leader has impacted your satisfaction with your SD D N A SA engineering studies?

Please explain:

6. Your involvement in TEAMS has impacted your undergraduate course Yes No selections or major.

Please explain:

7. Did you participate in TEAMS because you needed to fulfill a service Yes No requirement for a scholarship, program or society? (If no, skip to question \#8) If yes, please list and \# of hours required:

8. If you participated in TEAMS outside of a scholarship/program requirement, please list the reason(s) you desired to participate in leading an afterschool club.

9. What is the greatest benefit that you feel you are getting/got out of leading a TEAMS Club?

Please explain:

If your schedule allows, will you lead a TEAMS Club again next semester? $\quad$ Yes $\quad$ No

Is there anything else you'd like to add about your experience leading a club? 